MAGALHÃES, L.M. et al. Avaliação de protocolos do anestésico etomidato em Phrynops geofroanus. PUBVET, Londrina, V. 5, N. 21, Ed. 168, Art. 1130, 2011.

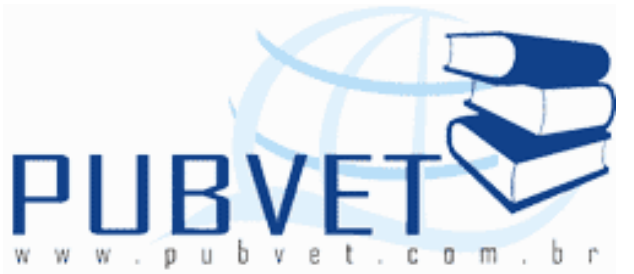

PUBVET, Publicações em Medicina Veterinária e Zootecnia.

\title{
Avaliação de protocolos do anestésico etomidato em Phrynops geofroanus
}

\section{Lívia Monteiro Magalhães ${ }^{1}$; André Luiz Quagliatto Santos ${ }^{2}$; Millene Torres de Oliveira ${ }^{3}$; Driele Schneidereit Sant'ana ${ }^{3}$; Leonardo Gomes Carrazza ${ }^{3}$; Thaís Gomes Carrazza ${ }^{1}$}

${ }^{1}$ Médica Veterinária

${ }^{2}$ Professor Dr. da Universidade Federal de Uberlândia

3 Mestrado/a do Programa de Pós-graduação em Medicina Veterinária da Universidade Federal de Uberlândia

\section{Resumo}

A administração de anestésicos assume importância crucial quando se deseja realizar exames clínicos e até mesmo realizar tratamentos na medicina de répteis. Nesse sentido, objetivou-se testar diferentes protocolos do anestésico etomidato na espécie Phrynops geoffroanus. Para tal, os cágados foram divididos em grupos de dez e anestesiados com diferentes protocolos de etomidato: o grupo $1(\mathrm{G} 1$ ) recebeu $1,0 \mathrm{mg} / \mathrm{kg}$ IV; o grupo 2 (G2) recebeu 1,5 $\mathrm{mg} / \mathrm{kg}$ IV o grupo 3 (G3) recebeu $3,0 \mathrm{mg} / \mathrm{kg}$ IV. Os parâmetros foram observados nos tempos de: 5, 10, 20, 30, 45, 60, 90, 120, 150, 180 minutos; sendo que tempo zero foi considerado o momento da administração da droga. Os parâmetros avaliados foram: locomoção, relaxamento, manipulação, resposta ao estímulo dos membros torácicos e pelvinos e batimentos 
MAGALHÃES, L.M. et al. Avaliação de protocolos do anestésico etomidato em Phrynops geofroanus. PUBVET, Londrina, V. 5, N. 21, Ed. 168, Art. 1130, 2011.

cardíacos. Para tais averiguações, foram atribuídos escores de 1; 2 e 3 sendo baixa, média e alta resposta aos estímulos respectivamente. Os animais foram considerados anestesiados quando seus escores somaram 11. Os resultados foram avaliados utilizando a ANOVA e teste Tukey com $5 \%$ de probabilidade e Friedman.. Dessa forma, observou que o etomidato, na dose de $1,0 \mathrm{mg} / \mathrm{Kg}$ e $1,5 \mathrm{mg} / \mathrm{Kg}$ são indicados para situações que exijam sedação satisfatória em Phrynops geoffroanus, como procedimentos clínicos e coleta de amostras biológicas, em temperatura ótima.

Palavras-chave: anestésico; cágados; protocol

\title{
Evaluation of protocols of anesthetic etomidate in Phrynops geofroanus
}

\begin{abstract}
The administration of anesthetics is crucial when considering performing clinical examinations and even carry out treatments in medicine of reptiles. Accordingly, the objective was to test different protocols of etomidate in anesthetic Phrynops geoffroanus species. To this end, the turtles were divided into groups of ten and anesthetized with etomidate different protocols: group 1 (G1) received $1.0 \mathrm{mg} / \mathrm{kg}$ IV, group 2 (G2) received $1.5 \mathrm{mg} / \mathrm{kg}$ IV group 3 (G3) received $3.0 \mathrm{mg} / \mathrm{kg}$ IV. The parameters were observed in intervals of 5 , $10,20,30,45,60,90,120,150,180$ minutes and that time zero was considered the time of drug administration. The parameters were assessed: mobility, relaxation, handling, response to stimulus in the thoracic and pelvic and heart rate. For this investigation were assigned scores of 1,2 and 3 being low, medium and high response to stimuli respectively. The anesthetized animals were considered when their scores totaled 11 . The results were evaluated using ANOVA (BANZATTO; KRONKA, 1995) and Tukey's test at 5\% probability and Friedman. Thus observed that etomidate at a dose of 1.0 $\mathrm{mg} / \mathrm{Kg}$ and $1.5 \mathrm{mg} / \mathrm{Kg}$ are recommended for situations requiring satisfactory
\end{abstract}


MAGALHÃES, L.M. et al. Avaliação de protocolos do anestésico etomidato em Phrynops geofroanus. PUBVET, Londrina, V. 5, N. 21, Ed. 168, Art. 1130, 2011.

sedation in Phrynops geoffoanu as clinical procedures and collection of biological sample at optimum temperature.

Keywords: anesthetic; tortoises; protocol

\section{INTRODUÇÃO}

A utilização de anestésicos faz-se necessária para a realização de exames físicos, procedimentos clínicos e cirúrgicos na medicina de répteis. No entanto, muito do que se conhece em anestesia para esses animais, é baseado em impressões da clínica e casos apresentados por veterinários com experiência em répteis. Pouco se sabe a respeito dos efeitos dos anestésicos nestes animais, em parte, por causa dos raros estudos e investigações (HINSCH; GANDAL, 1969; KANUI; HOLE, 1992).

$\mathrm{Na}$ década de 70 e início da década de 80 esses animais eram submetidos a imobilização e anestesia através da hipotermia e inalação de éter, sendo que atualmente considera-se que essas técnicas são ineficazes, de alto risco e para alguns (BENNETT, 1996) até desumanas. Á medida em que se aprofundam os conhecimentos anatômicos, fisiológicos e de anestesia dos répteis, é possível desenvolver protocolos eficazes e seguros.

A ordem Chelonia é constituída por tartarugas, cágados e jabutis. A principal característica dessa ordem é o casco que reveste o corpo do animal, formado por carapaça (dorsal) e plastrão (ventral). Esses animais possuem diferentes habitats: espécies exclusivamente terrestres como os jabutis (Geochelonia sp); espécies que vivem em ambientes fluviais e lacustres como os cágados (Phrynops sp); espécies exclusivamente marinhas como as tartarugas (Caretta caretta), e ainda, espécies que vivem em ambientes terrestre e de água doce como a Aperema (Rhynoclemmys punctularia) (GARCIA-NAVARRO; PACHALY, 1994). 
MAGALHÃES, L.M. et al. Avaliação de protocolos do anestésico etomidato em Phrynops geofroanus. PUBVET, Londrina, V. 5, N. 21, Ed. 168, Art. 1130, 2011.

A Phrynops geoffroanus pertence ao filo Chordata, ao subfilo Vertebrata, a superclasse Tetrapoda, a classe Reptilia e a ordem Chelonia (BENZZONI, 1972; GRASSÉ, 1978; MORANDINI, 1968).

Bennett (1991) e Boyer (1992), ao estudarem anestesia em quelônios, observaram que muitas técnicas foram testadas, mas a maioria apresentava limitações e efeitos colaterais, demonstrando que conhecimentos de sedação e anestesia são limitados nesses animais.

Nos últimos anos, alguns trabalhos vêm sendo publicados com a utilização de etomidato na anestesia de répteis. Ávila Júnior (2005) anestesiou 60 Podocnemis expansa (tartaruga da amazônia) utilizando diferentes protocolos, dentre eles: etomidato, etomidato associado com butorfanol e etomidato com fentanila.

Este trabalho tem como objetivo avaliar os efeitos anestésicos de diferentes protocolos de etomidato em Phrynops geoffroanus, visando determinar qual o mais seguro, eficiente e adequado protocolo para cada situação clínica e cirúrgica que envolva a espécie em questão.

\section{REVISÃO DE LITERATURA}

Segundo Randall, Burggren e French (2002), os répteis são animais ectotérmicos, ou seja, animais que necessitam de calor oriundo do meio. Possuem temperatura corpórea baixa, o que impedem que o metabolismo seja acelerado, pois as reações enzimáticas são termo-dependentes. Esse aspecto é de grande importância para a absorção e depuração das drogas, portanto influenciam na anestesia com longo período de indução e recuperação.

Os répteis possuem um sistema circulatório diferente dos mamíferos. Além das diferenças cardíacas, possuem um sistema porta-renal, onde parte do sangue proveniente das porções caudais do corpo é desviado para os rins (ORR, 1986).

Devido à presença do sistema porta renal, é aconselhável fazer administrações de drogas injetáveis nos membros torácicos, para que se evite 
MAGALHÃES, L.M. et al. Avaliação de protocolos do anestésico etomidato em Phrynops geofroanus. PUBVET, Londrina, V. 5, N. 21, Ed. 168, Art. 1130, 2011.

filtragem imediata pelo parênquima renal (MAUTINO; PAGE， 1993). Em estudos mais recentes, Holz et al. (1997) mostram que o local de administração de gentamicina não tem efeito sobre nenhum parâmetro farmacocinético. Segundo Benson e Forrest (1999), o sangue transportado pelo sistema porta-renal chega aos rins na altura das arteríolas eferentes e, portanto substâncias de filtragem glomerular não sofrem efeitos farmacocinéticos quando administradas na região pélvica.

Alguns estudos têm sido feitos para definir quais drogas são seguras para administrar caudalmente e quais não são (BECK; LOOMIS; LEWBART, 1995).

O principal parâmetro a ser aferido é a freqüência cardíaca, porém o coração tricavitário da maioria dos répteis é muito pouco audível com estetoscópio. Uma alternativa é o uso de estetoscópio esofágico. Entretanto, métodos como eletrocardiograma e a avaliação com doppler tem sido ferramentas fundamentais para o acompanhamento do paciente (BENNETT, 1996).

Frye (1991) acredita que o uso do doppler é o melhor caminho para a aferição da freqüência cardíaca, pois o aparelho produz sons audíveis.

A freqüência respiratória também deve ser observada. Entretanto sabese que os répteis podem fazer apnéia e respiração anaeróbia. A coloração da mucosa oral pode ser observada e em caso de cianose a ventilação assistida é recomendada (FRYE, 1991).

De acordo com Bennett (1991) a recuperação da anestesia é, em geral, lenta. Conhecendo as particularidades anatômicas e fisiológicas dos répteis pode-se, de certa forma, acelerá-la. Duas técnicas principais podem ser usadas, manter o animal em temperatura ótima (temperatura em que o animal apresenta seu metabolismo em melhor funcionamento, geralmente varia de 24 a $30^{\circ} \mathrm{C}$ ); e fazer ventilação assistida em caso de apnéia.

Um fármaco utilizado em anestesias na medicina veterinária é o etomidato. Este é um imidazol, pouco solúvel em água (EVERS; CROWDER, 2003), de peso molecular 244,28 e pH 5 (MASSONE, 1999). É um potente 
MAGALHÃES, L.M. et al. Avaliação de protocolos do anestésico etomidato em Phrynops geofroanus. PUBVET, Londrina, V. 5, N. 21, Ed. 168, Art. 1130, 2011.

agente hipnótico, sem propriedades analgésicas (FANTONI; CORTOPASSI; BERNARDI, 1999). Utilizado na indução da anestesia, bem como em técnicas de anestesia balanceada que não exigem sua administração prolongada. Sua principal vantagem é que a droga exerce efeitos cardiovasculares e respiratórios mínimos (ausência de qualquer efeito sobre a freqüência cardíaca e baixa freqüência de apnéia) (TREVOR; MILLER, 2002).

Massone (1999) afirma que o etomidato é um fármaco que pouca alteração causa a nível cardiorrespiratório e hemogasométrico. A nível de pressão intracraniana, ocorre uma discreta redução. Mioclonias podem ser observadas por estímulos acústicos ou ópticos, o que é um forte indício de desacoplamento entre estruturas cerebrais e medulares.

Aproximadamente $75 \%$ do etomidato ligam-se à albumina plasmática, sendo rapidamente distribuído pelo corpo. Possui curta duração de efeito, promovendo anestesia que não ultrapassa 10 a 15 minutos. Seu mecanismo de ação ainda não foi completamente elucidado, porém acredita-se que pode modular a neurotransmissão feita pelo GABA (FANTONI; CORTOPASSI; BERNARDI, 1999). A formação reticular cerebral parece ser o local da ação hipnótica (THURMON; TRANQUILLI; BENSON, 1996). Seu metabolismo ocorre no fígado e a eliminação é por via renal e biliar (EVERS; CROWDER, 2003).

O etomidato não potencializa o pancurônio e a succinilcolina; entretanto, potencializa as fenotiazinas e benzodiazepinas, é um fármaco de ação curta, tendo como aproveitamento, além da sua ação fortemente hipnótica, uma ação indutora para anestesia volátil (MASSONE, 1999).

Segundo Thurmon, Tranquilli e Benson (1996), o etomidato é uma droga semelhante ao metomidato. De acordo com Schumacher (1996), já foi relatado o uso de metomidato para sedação de serpentes, e por não apresentar propriedades analgésicas, deve ser usado apenas como agente sedativo ou medicação pré-anestésica. 
MAGALHÃES, L.M. et al. Avaliação de protocolos do anestésico etomidato em Phrynops geofroanus. PUBVET, Londrina, V. 5, N. 21, Ed. 168, Art. 1130, 2011.

\section{MATERIAL E MÉTODO}

Foram utilizadas 30 Phrynops geoffroanus (cágado de barbicha), provenientes do rio Uberabinha, Uberlândia MG, clinicamente saudáveis, de ambos os sexos, e peso variando de 0,400 a 3,550 quilos. O experimento foi conduzido nos anexos do Hospital Veterinário, Uberlândia MG.

A pesquisa foi realizada no mês de novembro, em que as condições climáticas eram de temperatura amena e tempo úmido, sendo que a temperatura oscilou entre 28 e 30 graus Celsius. A temperatura ambiental era aferida de hora em hora, com termômetro de máxima e mínima ${ }^{1}$.

Os animais foram capturados do rio e trazidos para o local do estudo, onde foram mantidos em uma piscina de fibra de vidro. Os espécimes foram pesados em balança pesadora simples (modelo 9094 - marca Toledo) e identificados no casco utilizando fita crepe com numeração seqüencial. Antes de realizar o experimento, foram aferidos os batimentos cardíacos de todos os répteis.

A administração do anestésico foi feita por via direta no seio vertebral cervical, mediante previa anti-sepsia e uso de seringas estéreis de $3 \mathrm{~mL}$, acopladas a agulhas hipodérmicas $25 \times 0,7 \mathrm{~mm}$.

Os cágados foram divididos em grupos de dez e anestesiados com diferentes protocolos de etomidato ${ }^{2}$ : o grupo 1 (G1) recebeu $1,0 \mathrm{mg} / \mathrm{kg} \mathrm{IV;} \mathrm{o}$ grupo 2 (G2) recebeu $1,5 \mathrm{mg} / \mathrm{kg}$ IV o grupo 3 (G3) recebeu 3,0 mg/kg IV.

Os parâmetros foram observados nos determinados tempos: 5, 10, 20, $30,45,60,90,120,150,180$ minutos; sendo que tempo zero foi considerado o momento da administração da droga. Os parâmetros avaliados foram os seguintes:

Locomoção: capacidade de se locomover normalmente, dificuldade de locomoção e ausência de locomoção;

\footnotetext{
${ }^{1}$ Incoterm, Porto Alegre, RS

${ }^{2}$ Etomidato 2,0mg/mL Cristália
} 
MAGALHÃES, L.M. et al. Avaliação de protocolos do anestésico etomidato em Phrynops geofroanus. PUBVET, Londrina, V. 5, N. 21, Ed. 168, Art. 1130, 2011.

Relaxamento muscular: capacidade de manter a cabeça elevada, facilidade de estender os membros do animal;

Manipulação: facilidade de manipular manualmente (flexão e extensão) a cabeça, os membros, a cauda e a boca do animal;

Resposta ao estímulo dos membros torácicos e pelvinos: pinçamento das falanges com pinça hemostática Kelly reta de $16 \mathrm{~cm}$, na primeira trava;

Batimentos cardíacos: aferição dos batimentos cardíacos pelo Doppler vascular $^{3}$, nos tempos $0,10,30,60,120$ e 180 minutos.

Um escore subjetivo de 1 para efeito mínimo, 2 para efeito médio e 3 para máximo efeito foi utilizado para os três primeiros parâmetros. Para os testes de resposta ao estímulo dos membros, a resposta ao pinçamento foi considerada escore 0 e, a ausência da resposta ao pinçamento foi considerada escore 1.

Os escores eram anotados em fichas anestesiológicas individuais. Os répteis foram considerados anestesiados quando o somatório de seu escore foi 11; e considerados recuperados quando suas atividades se aproximavam às de antes da administração das drogas. O tempo entre a administração dos anestésicos e a recuperação dos animais foi observado, considerado como retorno.

A análise estatística foi feita levando-se em consideração quanto tempo (minutos) os animais permaneceram em escore três, em escore dois e quanto tempo eles gastaram para retornar ao escore um para os parâmetros locomoção, relaxamento muscular e manipulação. Para os parâmetros resposta ao estímulo dos membros torácico e pelvino, levou-se em conta quanto tempo os espécimes mantiveram-se em escore um, e quanto tempo demoraram a voltar para o escore zero.

Os resultados foram avaliados utilizando a análise de variância (BANZATTO; KRONKA, 1995) para verificar a ocorrência de diferenças significativas entre os tratamentos. Ocorrendo diferenças, utilizou-se o teste de

\footnotetext{
${ }^{3}$ Modelo DV-20, Microem, Ribeirão Preto, SP
} 
MAGALHÃES, L.M. et al. Avaliação de protocolos do anestésico etomidato em Phrynops geofroanus. PUBVET, Londrina, V. 5, N. 21, Ed. 168, Art. 1130, 2011.

comparação múltipla de Tukey a 5\% de probabilidade (BANZATTO; KRONKA, 1995). Para a avaliação da influência do anestésico na freqüência cardíaca, foi realizado o teste de Friedman (BANZATTO; KRONKA, 1995).

\section{RESULTADOS}

Todos os répteis estudados obtiveram escore três (grau máximo de efeito) para os parâmetros locomoção e relaxamento muscular em até dois minutos após a administração do anestésico. O G3 foi o único grupo onde todos os animais entraram em anestesia, ou seja, obtiveram escore 11. No G1 e G2 nenhum dos cágados entrou em anestesia. No entanto, todos os animais do G2 atingiram escore três também para o parâmetro manipulação em até dois minutos após a administração do etomidato. Apenas quatro animais do G1 obtiveram escore três para manipulação.

Em relação à resposta ao estímulo do membro torácico, no G2 todos os animais alcançaram escore um, ou seja, ausência de resposta ao estímulo; enquanto que no $\mathrm{G} 1$ oito répteis alcançaram escore um para o mesmo parâmetro. Em ambos os grupos ( $\mathrm{G} 1$ e G2) todos os animais mantiveram-se em escore zero para resposta ao estímulo do membro pelvino, ou seja, respondiam ao estímulo quando pinçados.

Todos os répteis foram acompanhados até o retorno das suas atividades. Em todos os grupos, nenhum animal apresentou apnéia e veio a óbito.

Verificou-se que o G1, o G2 e o G3 apresentaram em média 93, 132 e 196 minutos respectivamente de tempo de recuperação. No G3, um animal recuperou-se da anestesia depois de 24 horas após administração do etomidato, tempo muito superior aos outros cágados do mesmo grupo. 
MAGALHÃES, L.M. et al. Avaliação de protocolos do anestésico etomidato em Phrynops geofroanus. PUBVET, Londrina, V. 5, N. 21, Ed. 168, Art. 1130, 2011.

Tabela 1 - Resumo da análise de variância para as variáveis TLoc3(tempo em que o animal permaneceu em escore três para locomoção), TLoc2 (tempo em que o animal permaneceu em escore dois para locomoção) e TVLoc1 (tempo que o animal demorou a voltar ao escore um para locomoção).

\begin{tabular}{|c|c|c|c|}
\hline \multirow[b]{2}{*}{ F.V. G.L. } & \multicolumn{3}{|c|}{ Quadrado médio } \\
\hline & TLoc3 & TLoc2 & TVLoc1 \\
\hline Trat. 2 & $4729,65^{*}$ & $3514,22^{*}$ & $20873,62 *$ \\
\hline Res. 26 & 621,92 & 818,26 & 860,38 \\
\hline CVE & $29,53 \%$ & $28,78 \%$ & $11,63 \%$ \\
\hline
\end{tabular}

Pode-se observar que os tratamentos apresentaram diferenças estatísticas significativas entre si em relação ao tempo em que os animais permaneceram em escore três e dois e no tempo que os espécimes demoraram a retornar ao escore um para o parâmetro locomoção.

Tabela 2 - Estimativas de médias para as variáveis TLoc3 (tempo em que o animal permaneceu em escore três para locomoção), TLoc2 (tempo em que o animal permaneceu em escore dois para locomoção) e TVLoc1 (tempo que o animal demorou a voltar ao escore um para locomoção)

\begin{tabular}{llll}
\hline & \multicolumn{3}{c}{ Médias } \\
\cline { 2 - 4 } Trat. & TLoc3 & TLoc2 & TVLoc1 \\
\hline T1,0mg & $17 \mathrm{a}$ & $34,5 \mathrm{a}$ & $93 \mathrm{a}$ \\
T1,5mg & $37 \mathrm{ab}$ & $43,5 \mathrm{ab}$ & $132 \mathrm{~b}$ \\
T3,0mg & $61 \mathrm{~b}$ & $71,6 \mathrm{~b}$ & $186 \mathrm{c}$ \\
\hline
\end{tabular}

Para análise os dados foram transformados para $\sqrt{ } x+0,5$.

Médias seguidas de letras iguais na coluna não diferem estatisticamente pelo teste Tukey a $5 \%$ de probabilidade. 
MAGALHÃES, L.M. et al. Avaliação de protocolos do anestésico etomidato em Phrynops geofroanus. PUBVET, Londrina, V. 5, N. 21, Ed. 168, Art. 1130, 2011.

De acordo com a tabela 2, para as variáveis TLoc3 e TLoc2, o tratamento utilizado no $\mathrm{G} 1(1,0 \mathrm{mg} / \mathrm{Kg})$ não difere estatisticamente do utilizado no $\mathrm{G} 2(1,5 \mathrm{mg} / \mathrm{Kg})$; o tratamento realizado no $\mathrm{G} 2$ não difere estatisticamente do utilizado no $\mathrm{G} 3(3,0 \mathrm{mg} / \mathrm{Kg})$ e o tratamento utilizado no $\mathrm{G} 1$ difere estatisticamente do G3.

Para a variável TVLoc1, todos os tratamentos diferem-se estatisticamente entre si.

Observa-se que houve diferenças significativas entre os tratamentos em relação ao tempo de permanência dos animais em escore três e dois e o tempo gasto para os répteis retornarem ao escore um para o parâmetro relaxamento muscular.

Tabela 3 - Resumo da análise de variância para as variáveis TRM3 (tempo em que o animal permaneceu em escore três para relaxamento muscular), TRM2 (tempo em que o animal permaneceu em escore dois para relaxamento muscular), TVRM1 (tempo que o animal demorou a voltar ao escore um para relaxamento muscular).

\begin{tabular}{|c|c|c|c|c|}
\hline \multirow{2}{*}{\multicolumn{2}{|c|}{ F.V. G.L. }} & \multicolumn{3}{|c|}{ Quadrado médio } \\
\hline & & TRM3 & TRM2 & TVRM1 \\
\hline Trat & 2 & $2112,93^{*}$ & $8641,85^{*}$ & $21638,23^{*}$ \\
\hline Res & 26 & 488,46 & 646,25 & 826,63 \\
\hline CVE & & $30,36 \%$ & $25,13 \%$ & $11,85 \%$ \\
\hline
\end{tabular}

De acordo com a tabela 4, para a variável TRM3 o G1 não difere estaticamente do G2 e este por sua vez, não difere estatisticamente do G3.

Para a variável TRM2, o G1 e G2 não diferem estatisticamente entre si. Já o G3 apresenta diferença estatística em relação aos demais.

Para a variável TVRM1, os três grupos apresentam diferenças estatísticas entre si. 
MAGALHÃES, L.M. et al. Avaliação de protocolos do anestésico etomidato em Phrynops geofroanus. PUBVET, Londrina, V. 5, N. 21, Ed. 168, Art. 1130, 2011.

Tabela 4 - Estimativas de médias para as variáveis TRM3 (tempo em que o animal permaneceu em escore três para relaxamento muscular), TRM2 (tempo em que o animal permaneceu em escore dois para relaxamento muscular), TVRM1 (tempo que o animal demorou a voltar ao escore um para relaxamento muscular).

\begin{tabular}{llll}
\hline & \multicolumn{3}{c}{ Médias } \\
\cline { 2 - 4 } Trat. & TRM3 & TRM2 & TVRM1 \\
\hline T1,0mg & $17 a$ & $32 \mathrm{a}$ & $91,5 \mathrm{a}$ \\
T1,5mg & $34 \mathrm{ab}$ & $44 \mathrm{a}$ & $129 \mathrm{~b}$ \\
T3,0mg & 46b & $90 \mathrm{~b}$ & $186,6 \mathrm{c}$ \\
\hline
\end{tabular}

Para análise os dados foram transformados para $\sqrt{ } \mathrm{x}+0,5$.

Médias seguidas de letras iguais na coluna não diferem estatisticamente pelo teste Tukey a $5 \%$ de probabilidade.

Tabela 5 - Resumo da análise de variância para as variáveis TEMT1 (tempo que o animal permaneceu em escore um para resposta ao estímulo do membro torácico), TVEMTO (tempo que o animal demorou a voltar ao escore zero para resposta ao estímulo do membro torácico).

\begin{tabular}{|c|c|c|}
\hline \multirow[b]{2}{*}{ F.V. G.L. } & \multicolumn{2}{|c|}{ Quadrado médio } \\
\hline & TEMT1 & TVEMTO \\
\hline Trat. 2 & $4562,99 \mathrm{~ns}$ & $6772,02 \mathrm{~ns}$ \\
\hline Res. 26 & 1746,94 & 2540,48 \\
\hline CVE & $43,53 \%$ & $37,45 \%$ \\
\hline
\end{tabular}

A tabela acima exibe que não há diferenças estatísticas entre os tratamentos, levando-se em conta as variáveis TEMT1 e TVEMTO. 
MAGALHÃES, L.M. et al. Avaliação de protocolos do anestésico etomidato em Phrynops geofroanus. PUBVET, Londrina, V. 5, N. 21, Ed. 168, Art. 1130, 2011.

Tabela 6 - Estimativas de médias para as variáveis TEMT1 (tempo que o animal permaneceu em escore um para resposta ao estímulo do membro torácico), TVEMTO (tempo que o animal demorou a voltar ao escore zero para resposta ao estímulo do membro torácico).

\begin{tabular}{lll}
\hline & \multicolumn{2}{c}{ Médias } \\
\cline { 2 - 3 } Trat. & TEMT1 & TVEMT0 \\
\hline T1,0g & $33,5 \mathrm{a}$ & $52,5 \mathrm{a}$ \\
T1,5g & $57,2 \mathrm{a}$ & $86,0 \mathrm{a}$ \\
T3,0g & $77,2 \mathrm{a}$ & $105 \mathrm{a}$ \\
\hline
\end{tabular}

Para análise os dados foram transformados para $\sqrt{ } \mathrm{x}+0,5$.

Médias seguidas de letras iguais na coluna não diferem estatisticamente pelo teste Tukey a $5 \%$ de probabilidade.

Conforme a tabela 6, o G1, G2 e G3 não diferem estatisticamente entre si em relação ao tempo de permanência dos animais em escore um e o tempo gasto de volta dos mesmos ao escore zero para o parâmetro de resposta ao estímulo do membro torácico

Tabela 7 - Resumo da análise de variância para as variáveis TEMP1 (tempo que o animal permaneceu em escore um para resposta ao estímulo do membro pelvino), TVEMPO (tempo que o animal demorou a voltar ao escore zero para resposta ao estímulo do membro pelvino).

\begin{tabular}{llll}
\hline & \multicolumn{2}{c}{ Quadrado médio } \\
\cline { 2 - 3 } F.V. & G.L. & TEMP1 & TVEMP0 \\
\hline Trat. & 2 & $1456,89 *$ & $4965,51^{*}$ \\
Res. & 26 & 53,84 & 121,15 \\
\hline CVE & $34,3 \%$ & $30,6 \%$ \\
\hline $\begin{array}{l}\text { Para análise os dados foram transformados para } \sqrt{ } \times+0,5 \\
\text { *Diferenças significativas ao nivel de probabilidade de } 0,05 .\end{array}$
\end{tabular}

Nota-se que os tratamentos apresentam diferenças significativas entre si em relação ao tempo de permanência dos animais em escore um e o tempo 
MAGALHÃES, L.M. et al. Avaliação de protocolos do anestésico etomidato em Phrynops geofroanus. PUBVET, Londrina, V. 5, N. 21, Ed. 168, Art. 1130, 2011.

que os répteis utilizaram para retornar ao escore zero para o parâmetro de resposta ao estímulo do membro pelvino.

Tabela 8 - Estimativas de médias para as variáveis TEMP1 (tempo que o animal permaneceu em escore um para resposta ao estímulo do membro pelvino), TVEMPO (tempo que o animal demorou a voltar ao escore zero para resposta ao estímulo do membro pelvino).

\begin{tabular}{lcc}
\hline & & Médias \\
\cline { 2 - 3 } Trat. & TEMP1 & TVEMP0 \\
\hline T1,0g & $0,0 \mathrm{a}$ & $0,0 \mathrm{a}$ \\
$\mathrm{T} 1,5 \mathrm{~g}$ & $0,0 \mathrm{a}$ & $0,0 \mathrm{a}$ \\
$\mathrm{T} 3,0 \mathrm{~g}$ & $21,6 \mathrm{~b}$ & $40 \mathrm{~b}$ \\
\hline
\end{tabular}

Para análise os dados foram transformados para $\sqrt{ } \mathrm{x}+0,5$.

Médias seguidas de letras iguais na coluna não diferem estatisticamente pelo teste Tukey a $5 \%$ de probabilidade.

De acordo com a tabela 8, para as variáveis TEMP1 e TVEMP0 o G1 não difere estatisticamente do G2 e o G3 difere estatisticamente dos demais.

Tabela 9 - Resumo da análise de variância para as variáveis TMan3 (tempo em que o animal permaneceu em escore três para manipulação), TMan2 (tempo em que o animal permaneceu em escore dois para manipulação), TVMan1 (tempo que o animal demorou a voltar ao escore um para manipulação).

\begin{tabular}{|c|c|c|c|c|}
\hline \multirow[b]{2}{*}{ F.V. } & \multirow[b]{2}{*}{ G.L. } & \multicolumn{3}{|c|}{ Quadrado médio } \\
\hline & & TMan3 & TMan2 & TVMan1 \\
\hline Trat. & 2 & $2556,33^{*}$ & $1844,09 *$ & $19947,41^{*}$ \\
\hline Res. & 26 & 409,32 & 393,55 & 1142,3 \\
\hline$\overline{\text { CVE }}$ & & $49,93 \%$ & $28,76 \%$ & $19,27 \%$ \\
\hline
\end{tabular}


MAGALHÃES, L.M. et al. Avaliação de protocolos do anestésico etomidato em Phrynops geofroanus. PUBVET, Londrina, V. 5, N. 21, Ed. 168, Art. 1130, 2011.

Observa-se que os tratamentos apresentaram diferenças significativas entre si em relação ao tempo em que os animais permaneceram em escore três e dois e no tempo que os espécimes demoraram a retornar ao escore um para o parâmetro manipulação.

Tabela 10 - Estimativas de médias para as variáveis TMan3 (tempo em que o animal permaneceu em escore três para manipulação), TMan2 (tempo em que o animal permaneceu em escore dois para manipulação), TVMan1 (tempo que o animal demorou a voltar ao escore um para manipulação).

\begin{tabular}{llll}
\hline & \multicolumn{3}{c}{ Médias } \\
\cline { 2 - 4 } Trat. & TMan3 & TMan2 & TVMan1 \\
\hline T1,0mg & $4,0 \mathrm{a}$ & $15,5 \mathrm{a}$ & $39 \mathrm{a}$ \\
T1,5mg & $16,5 \mathrm{a} \mathrm{b}$ & $27,0 \mathrm{a} \mathrm{b}$ & $72 \mathrm{~b}$ \\
T3,0mg & $36,66 \mathrm{~b}$ & $43,33 \mathrm{~b}$ & $130 \quad \mathrm{c}$ \\
\hline Para análise os dados foram transformados para $\sqrt{ } \mathrm{x}+0,5$. & \\
Médias seguidas de letras iguais na coluna não diferem estatisticamente pelo teste Tukey a $5 \%$ de probabilidade.
\end{tabular}

Segundo a tabela 10, para as variáveis TMan3 e TMan2 o tratamento utilizado no G1 não difere estatisticamente do utilizado no G2; o tratamento realizado no G2 não difere estatisticamente do utilizado no G3 e o tratamento utilizado no G1 difere estatisticamente do empregado no G3.

Para a variável TVMan1, todos os tratamentos diferem-se estatisticamente entre si.

\section{DISCUSSÃO}

O estudo foi realizado em ambiente natural dos animais, onde a temperatura oscilou entre 28 e 32 graus Celsius. Essa temperatura é considerada ótima, onde o animal apresenta seu metabolismo em melhor funcionamento (BENNETT, 1991). Portanto, foi esperada a maior ação possível das drogas utilizadas. 
MAGALHÃES, L.M. et al. Avaliação de protocolos do anestésico etomidato em Phrynops geofroanus. PUBVET, Londrina, V. 5, N. 21, Ed. 168, Art. 1130, 2011.

A sedação foi obtida em todos os animais estudados e o período de indução foi menor que dois minutos. Fatos que são justificados pela escolha do anestésico é o fato de ser uma droga de rápido efeito (TREVOR; MILLER, 2002), e pela via de administração, pois o seio vertebral cervical pode facilitar a distribuição pelo sistema nervoso.

Segundo Leitão et al. (1991), a estabilidade cardiovascular observada após o uso de etomidato, associada ao fato da ausência de liberação de histamina, foram as suas principais vantagens inicialmente descritas. Tal afirmação está de acordo com o encontrado no experimento, pois em todos os grupos a freqüência cardíaca não foi alterada significativamente após a administração do medicamento.

Leitão et al. (1991) afirmam que o etomidato produz depressão respiratória, dose dependente, com redução do volume corrente da freqüência respiratória. Pode haver a ocorrência de apnéia, que entretanto, é transitória. No entanto, Trevor e Miller (2002) afirmam que o etomidato exerce efeitos respiratórios mínimos (baixa freqüência de apnéia). Massone (1999) relata que o etomidato é um fármaco que pouca alteração causa a nível cardiorrespiratório. Ávila Júnior (2005) ao anestesiar Podocnemis expansa revela que os animais tratados com etomidato não apresentaram apnéia o que também foi detectado neste experimento.

O etomidato é um agente hipnótico potente e de curta duração, e que não apresenta propriedade analgésica (LEITÃo et al., 1991). Bosso et al.(2006) ao anestesiar 30 Rana catesbeiana com etomidato nas doses de 2,0 $\mathrm{mg} / \mathrm{Kg}, 4,0 \mathrm{mg} / \mathrm{Kg}$ e $6,0 \mathrm{mg} / \mathrm{Kg}$, constataram a ausência de analgesia em todos os animais.

O mesmo resultado foi detectado no $G 1$ e $G 2$, pois os animais respondiam ao estímulo dos membros pelvinos quando pinçados. A não resposta ao estímulo dos membros torácicos e pelvinos no G3 em um determinado período da anestesia, não é indicativo de ausência de dor e sim do possível bloqueio das vias motoras. Daí pode-se concluir que o animal sente dor, porém não consegue retirar o membro. 
MAGALHÃES, L.M. et al. Avaliação de protocolos do anestésico etomidato em Phrynops geofroanus. PUBVET, Londrina, V. 5, N. 21, Ed. 168, Art. 1130, 2011.

Bennett (1996) relata que o progresso da anestesia em répteis ocorre em sentido crânio-caudal e durante a recuperação a função motora volta em sentido oposto, quando da administração do anestésico no membro torácico. A ausência de resposta ao estímulo dos membros torácicos associada à presença de reação ao estímulo dos membros pelvinos nos animais do $G 1$ e G2, pode ser explicada por um maior bloqueio das vias motoras dos membros torácicos devido à maior proximidade destes do local de administração do anestésico (seio vertebral cervical) em relação aos membros pelvinos.

É prática estabelecida administrar etomidato com fentanila (ALVES; DOREA; ANDRADE, 2002). Entretanto, Bennett (1996) afirma que os opióides são ineficazes nos répteis. Para Buatti e Pasternak (1981), existem diferenças nos receptores opióides entre diferentes espécies. Ávila Júnior (2005) relata que o butorfanol $(1 \mathrm{mg} / \mathrm{Kg})$ e a fentanila $(0,01 \mathrm{mg} / \mathrm{Kg})$ não acresceram analgesia, na anestesia de Podocnemis expansa, quando associados ao etomidato $(2 \mathrm{mg} / \mathrm{Kg})$. Tais afirmações evidenciam a necessidade de estudos mais profundos a respeito de mecanismos eficientes de bloqueio da dor em répteis.

O G3 foi o único grupo em que todos os animais atingiram escore 11 , ou seja, foram considerados anestesiados (ÁVILA JÚNIOR, 2005). No entanto, o experimento revela que esse protocolo não é indicado para anestesia cirúrgica, visto que o tempo de permanência dos animais com ausência de resposta ao estímulo dos membros pelvinos não é considerado satisfatório (em média 22 minutos).

O G1 e G2 não apresentaram diferenças estatísticas em relação há quanto tempo os animais permaneceram em escore três para os parâmetros locomoção, relaxamento muscular e manipulação. Também foram semelhantes estatisticamente levando-se em conta o tempo de permanência em escore um para resposta ao estímulo dos membros torácicos e a constância de resposta ao estímulo dos membros pelvinos durante todo o experimento. Os resultados obtidos demonstram que os protocolos utilizados em ambos os grupos são contra indicados para anestesia cirúrgica, já que todos os cágados não 
MAGALHÃES, L.M. et al. Avaliação de protocolos do anestésico etomidato em Phrynops geofroanus. PUBVET, Londrina, V. 5, N. 21, Ed. 168, Art. 1130, 2011.

atingiram escore 11, portanto não foram anestesiados. Ávila Júnior (2005) relata que do grupo com dez animais testados com etomidato $2,0 \mathrm{mg} / \mathrm{Kg}$ associado a butorfanol 1,0 mg/Kg, apenas duas tartarugas da Amazônia foram anestesiadas.

A utilização das doses testadas no $\mathrm{G} 1$ e $\mathrm{G} 2$ é recomendada para procedimentos clínicos, coleta de amostras biológicas em Phrynops geoffroanus, visto que os animais apresentaram locomoção, relaxamento muscular e manipulação satisfatórios. Como não houve diferenças significativas entre os dois grupos pode-se optar pela economia de anestésico utilizando o protocolo do $\mathrm{G} 1(1,0 \mathrm{mg} / \mathrm{Kg})$.

Verificou-se que o G1, o G2 e o G3 apresentaram em média 93, 132 e 196 minutos respectivamente de tempo de recuperação. De toda forma, todos os tratamentos podem ter seu tempo de retorno considerado rápido, já que os anestésicos dissociativos apresentam períodos de recuperação bastante prolongados (SCHILLIGER, 2000), podendo exceder 24 horas.

No G3, um animal recuperou-se da anestesia depois de 24 horas após administração do etomidato, tempo muito superior aos outros animais do mesmo grupo. Fatores individuais como alguma deficiência de metabolização ou excreção da droga, podem justificar o ocorrido (ÁVILA JÚNIOR, 2005).

A não ocorrência de óbitos demonstrou a segurança dos protocolos e da via de administração adotada. O mesmo resultado foi encontrado por Ávila Júnior (2005) ao anestesiar Podocnemis expansa com etomidato.

\section{CONCLUSÕES}

O etomidato, na dose de $3,0 \mathrm{mg} / \mathrm{Kg}$, embora seguro não foi eficiente para anestesia cirúrgica de Phrynops geoffroanus, sendo indicado para ocasiões que necessitem de uma satisfatória contenção farmacológica, em temperatura ótima. 
MAGALHÃES, L.M. et al. Avaliação de protocolos do anestésico etomidato em Phrynops geofroanus. PUBVET, Londrina, V. 5, N. 21, Ed. 168, Art. 1130, 2011.

O etomidato, na dose de $1,0 \mathrm{mg} / \mathrm{Kg}$ e $1,5 \mathrm{mg} / \mathrm{Kg}$ são indicados para situações que exijam sedação satisfatória em Phrynops geoffroanus, como procedimentos clínicos e coleta de amostras biológicas, em temperatura ótima.

\section{REFERÊNCIAS BIBLIOGRÁFICAS}

ALVES, T. C. A.; DOREA, E. M. L.; ANDRADE, R. F. Anestésicos Gerais Intravenosos. In: SILVA, P. Farmacologia. 6ed. Rio de Janeiro: Editora Guanabara Koogan S. A., 2002, p. 391-403.

ÁVILA JÚNIOR, R.H. Efeitos anestésicos do propofol e do etomidato isolados e associados com butorfanol e fentanila em tartaruga-da amazônia (Podocnemis expansa-Schweigger, 1812). 2005. 31 f. Dissertação (Mestrado)-Faculdade de Medicina Veterinária, Universidade Federal de Uberlândia, Uberlândia.

BAKALKIN,G.Y.A. et al. Lateralization of opiod receptors in turtle visual cortex. Brain Research. v.480 n.1-2 p. 268-276, 1989.

BANZATTO, D. A.; KRONKA, S. N. Experimentação agrícola, 3 ed., Jaboticabal: UNESP; FUNEP, 1995, 247p.

BECK K.; LOOMIS M.; LEWBART G.L. Preliminary comparison of plasma concentrations of gentamicin injected into the cranial and caudal limb musculature of the eastern box turtle (Terrapene carolina carolina). Journal of Zoo and Wildlife Medicine, Philadelphia, n. 26, p. 265-268, 1995.

BENNETT, R.A. A review of anesthesia and chemical restrain in reptiles. Journal of Zoo and Wildlife Medicine, Philadelphia, v. 22, p. 282-303, 1991.

BENNETT, R.A. Anesthesia. In: MADER, D.R. Reptile medicine and surgery. Philadelphia: W.B. Saunders, 1996, p. 241-247.

BENSON, K. G.; FORREST, L. Characterization of the renal portal system of the common green iguana (Iguana iguana) by digital subtraction imaging. Journal of Zoo and Wildlife Medicine, Philadelphia, v. 30, n. 2, p. 235-241, 1999.

BOYER, T. H. Clinical anesthesia for reptiles. Bulletin Association of Reptiles Amphibians Veterinarians, Paris, v.2, p. 10-13, 1992.

BUATTI; M.C.; PASTERNAK, G.W. Multiple opiate receptors: phylogenetic differences. Brain Research. v.218 n.1-2,p.400 - 405.1981.

CARVALHO, S. F. M. Anestesia dissociativa em tartarugas da Amazônia (Podocnemis expansa, Schweigger-1812) (Testudinata) e monitoramento cardíaco com eletrocardiógrafo. 2005. 68 f. Dissertação (Mestrado) - Faculdade de Medicina Veterinária, Universidade Federal de Uberlândia, Uberlândia, 2005.

ERNEST,C.H.; BARBOUR, R.W. Turtles of the world. Washington: Smithsonian Institution, 1989. 383 p. 
EVERS, A. S.; CROWDER, M. Anestésicos Gerais. In: HARDMAN, J. G.; LIMBIRD, L. E. Goodman \& Gilman As bases farmacológicas da terapêutica. 10 ed. Rio de Janeiro: McGraw-Hill Interamericana do Brasil LTDA., 2003 p. 257 - 278.

FANTONI, D.T.; CORTOPASSI, S.R.G.; BERNARDI, M.M. Anestésicos intravenosos e outros parenterais. In: SPINOSA, H.S.; GORNIAK, S.L.; BERNARDI, M.M. Farmacologia aplicada a medicina veterinária. 2.ed. Rio de Janeiro: Editora Gunabara Koogan S.A., 1999. 646p. p. 113-124.

FRYE, F.L. Anesthesia. In: FRYE, F.L. Reptile care na atlas of diseases and tratament volume II - Neptune City: T.F.H. Publication INC., 1991 p.421 - 437.

GARCIA-NAVARRO, C.E.K; PACHALY, J.R. 1994. Manual de hematologia veterinária, São Paulo: Livraria Varela, 1994. p. 69-71, 123-132.

HINSCH, H.; GANDAL, C.P. The effects of ethorphine (M-99), oxymorphone hydrochloride and meperidine hydrochloride in reptiles. Copeia, p.404-405, 1969.

HOLZ, P.; BARKER, I. K.; BURGER, J. P.; CONLON, P. D. The effect of the renal portal system on pharmacokinectic parameters in the red eared slider (Trachemis scripta elegans). Journal of Zoo and Wildlife Medicine, Philadelphia, v. 28, n. 4, p. 386-393, 1997.

HUBBELL, J. A. E. Métodos práticos de anestesia in manejo do paciente. In: BICHARD, S. J.; SHERDING, R. G. Manual saunders: clínica de pequenos animais, Tradução de Paulo Marcos Angria de Oliveira. 2. ed. São Paulo : Roca, 2003. Seção 1, cap. 2, p.14.

KANUI, T.I.; HOLE, K. Morphine and pethidine antinociception in the crocodile. Journal of Veterinary Pharmacological Therapy, v.15, p.101-103, 1992.

KAVALIERS, M.; COURTENAY, S.;HIRST, M. Opiates influence behavioral thermoregulation in curly-tailed lizard, Leiocephalus carinatus. Physiology Behavioral. v. 32 n.2, p. 221 - 224, 1984.

LEITÃO, F. B. P.; CAMARGO, E. A.; NETO, P. P. R. Anestésicos gerais. In:VALLE, L.B.S; OLIVEIRA FILHO, R.M.; LUCIA, R.; OLGA, S. Farmacologia Integrada. Rio de Janeiro: Atheneu, 1991, v.2, p.184-185.

MACHIN, K.L. Fish, amphibian, and reptile analgesia. Veterinary Clinics of North America: exotic animal practice. v. 4 n.1, p. $19-33,2001$.

MASSONE, F. Medicação pré-anestésica. In: Anestesiologia veterinária:

farmacologia e técnicas. 3. ed. Rio de Janeiro: Guanabara Koogan, 1999. p.17-30.

MAUTINO, M.; PAGE, D. Biology and medicine of turtle and tortoise. Veterinary Clinics of North America: Small animal practice. v. 23 n.6, p. 1251 - 1271, 1993.

ORR, R.T. Biologia dos Vertebrados. 5.ed. São Paulo: Editora Roca, 1986. 508p.

PIVOVAROV, A.S.; IZMEST'EV, V.I. Effect of blockade of the dopamine, serotonin and cholinergic receptors on opioid modification of habituation in the visual cortex of the turtle. Zh. Vyssh. Nerv. Deiat. Im. I. P. Pavlova. v. 37 n. 6 p. $1099-1109,1987$.

POUGH, F. H; HEISER, J. B.; MCFARLAND, W. N. A vida dos vertebrados. 2. ed. São Paulo: Atheneu, 1999. 356 p. 
RANDALL, D.; BURGGREN, W.; FRENCH, K. Eckert animal physiology mechanisms and adaptations. 5.ed. New York: W.H. Freman and Company, 2002. 736p.

SCHILLIGER, L. Anesthésie des reptiles - Anesthésie - Reanimation. In: Encyclopédie Vétérinaire .Paris: Editions Scientifiques et Médicales Elsevier. 6p.2000.

SCHUMACHER, J. Reptiles and Anphibians. In: THURMON, J.C.; TRANQUILLI, W.J. Lumb \& Jones Veterinary Anesthesia. Pennsylvania: Saunders., 1996 p 670-685.

THURMON, J.C.; TRANQUILLI, W.J. Injectable Anesthetics. In: THURMON, J.C.; TRANQUILLI, W.J. Lumb \& Jones Veterinary Anesthesia. Pennsylvania: Saunders. 1996. p 210-240.

TRAVOR, A. J.; MILLER, R. D. Anestésicos gerais. In: KATZUNG, B. G. Farmacologia Básica e Clínica. 8 ed. Rio de Janeiro: Editora Guanabara Koogan S., 2002. p. 367-380.

XIA, Y.; HADDAD, G.G. Major difference in the expression of delta and mu opioid receptors between turtle and rat brain. Journal Comp. Neurology. v. 436 n. 2. p. $202-210.2001$. 